\title{
Drought risk assessment in central Nepal: temporal and spatial analysis
}

\author{
Piyush Dahal $^{1}$ - Nicky Shree Shrestha ${ }^{1,2} \cdot$ Madan Lall Shrestha $^{1,3} \cdot$ \\ Nir Y. Krakauer ${ }^{4} \cdot$ Jeeban Panthi $^{1} \cdot$ Soni M. Pradhanang ${ }^{5}$ • \\ Ajay Jha $^{6} \cdot$ Tarendra Lakhankar $^{7}$
}

Received: 18 December 2014/ Accepted: 11 October 2015/Published online: 27 October 2015

(C) The Author(s) 2015. This article is published with open access at Springerlink.com

\begin{abstract}
This paper presents temporal and spatial pattern of drought phenomena in central Nepal using standardized precipitation index (SPI) at multiple time scales. The study is based on 32 years of monthly precipitation data from 40 meteorological stations from 1981 to 2012. Results indicate that, while there is no distinct trend in regional precipitation, interannual variation is large. Trend analysis of drought index shows that most stations are characterized by increases in both severity and frequency of drought and trend is stronger for longer drought time scales. Over the study period, the summer
\end{abstract}

Piyush Dahal

piyush.dahal@gmail.com

Nicky Shree Shrestha

sthanicky@gmail.com

Madan Lall Shrestha

madanls@hotmail.com

Nir Y. Krakauer

nkrakauer@ccny.cuny.edu

Jeeban Panthi

panthijeeban@gmail.com

Soni M. Pradhanang

soni.pradhanang@gmail.com

Ajay Jha

ajayjha1965@gmail.com

Tarendra Lakhankar

tlakhankar@ccny.cuny.edu

1 The Small Earth Nepal, 626-Bhakti Thapa Sadak, Naya Baneshwor, PO Box \# 20533, Kathmandu, Nepal

2 Kathmandu University, Dhulikhel, Nepal

3 Nepal Academy of Science and Technology, Khumaltar, Nepal

4 Department of Civil Engineering and NOAA-CREST Center, The City College of New York, New York, USA 
season of 2004, 2005, 2006, 2009 and winters 2006, 2008 and 2009 were the worst widespread droughts. These dry periods have a serious impact on agriculture-livestock production of central Nepal. Better understanding of these SPI dynamics could help in understanding the characteristics of droughts and also to develop effective mitigation strategies.

Keywords Drought · Precipitation · Standardized Precipitation Index (SPI) · Agriculture $\cdot$ Central Nepal

\section{Introduction}

Drought is a silent and pervasive hazard, which originates from the deficit of water availability, with devastating impacts on agriculture, water supply and the environment (Dow 2010; Popova et al. 2014; Yu et al. 2014) causing economic losses (Below et al. 2007; Wilhite 2000; Wilhite et al. 2007). In comparison with other natural hazards, drought tends to start slowly often without warning, lasts for significant period of time covering large spatial areas, and may linger for years after termination (Lena et al. 2013; Mishra and Singh 2010; Rossi et al. 1992). Recent studies show that the agricultural production has declined significantly in many parts of world including Asia due to increased frequency and severity of drought (Downing and Bakker 2000). For example, the severe Australian drought in 2006 reduced the national winter cereal crop by $36 \%$ leaving many farmers in financial crisis (Wong et al. 2010) and the European drought of 2003 reduced gross primary productivity by $30 \%$ (Ciais et al. 2005). The drought of 2010-2011 caused crop failures across Somalia, Ethiopia and Kenya which raised the price of maize in Kenya by $246 \%$ over the span of a year (Funk 2011). Drought has caused 70-80 billion kg per year food loss in China over the past century, corresponding to $17 \%$ of the total yield (Liu et al. 2013). Food grain production dipped by about $14 \%$ compared to previous year due to severe drought in India in 2002 (Nagaraja et al. 2011) and in Pakistan, overall agriculture production decreased by $2.6 \%$ during 2000-2001 drought (Ahmad et al. 2004). And droughts are projected to become more frequent and severe in future with increases in extreme climatic events (Trenberth et al. 2014).

In order to mitigate losses caused by drought in future, it is necessary to monitor and assess this phenomenon using scientific tools. Drought indices are very important tools to monitor and to assess drought (Heim 2002). Drought indices are normally continuous functions of rainfall and/or temperature, river discharge or other measurable variables, but

5 Department of Geosciences, University of Rhode Island, RI, USA

6 Institute for Global Agriculture \& Technology Transfer, 2144 Baldwin Street, Fort Collins, CO 80528, USA

7 NOAA-CREST Center, The City College of New York, New York, USA 
rainfall data are most widely used to calculate drought indices since long-term rainfall data are often readily available (Liu et al. 2014). Different indices are available globally to quantify drought, each with its own strengths and weaknesses. These include the Palmer Drought Severity Index (Palmer 1965), Standardized Precipitation Index (McKee et al. 1993), Standardized Precipitation Evapotranspiration Index (Vicente-Serrano et al. 2009), Effective Drought Index (Byun and Wilhite 1999), Rainfall Anomaly Index (Rooy 1965), Deciles (Gibbs and Maher 1967), Crop Moisture Index (Palmer 1968), Bhalme and Mooly Drought Index (Bhalme and Mooley 1980), Surface Water Supply Index (Shafer and Dezman 1982), and others (Mishra and Singh 2010). In this study, the standardized precipitation index (SPI), proposed by McKee et al. (1993), is used to analyze the characteristics of drought. The basic criteria of selection of SPI for this study are that it can be computed over a wide spectrum of time scales ranging from 1 to 72 months (Edwards and McKee 1997), and it uses only precipitation as an input, which has been observed for the longest time period and comparatively of good quality in this region. Regarding the analysis of agricultural drought, the appropriate time-scale should be limited to the cropgrowing season, but many drought indices do not support this. SPI is calculated using the long-term monthly rainfall record of a specific location. Since SPI is standardized and has a probabilistic interpretation, it can be used in risk assessment and decision-making (Guttman 1998).

Since drought directly affects crops leading to economic losses, the countries like Nepal where people are mostly dependent on rain-fed agriculture for their livelihoods are very much vulnerable to drought (Gentle and Maraseni 2012). Agriculture is the major income source of about $64 \%$ households of Nepal, and it accounts for $35 \%$ of the national GDP (Nepal Living Standards Survey 2010/11). In recent years, drought has emerged as a source of vulnerability in rainfed agriculture in Nepal particularly in hills and mountains (Ghimire et al. 2010; Gumma et al. 2011; Wang et al. 2013). In Nepal about $80 \%$ of the total annual rainfall occurs during the summer monsoon (June-September) (Shrestha 2000), which is the most important season for agriculture because summer crops (paddy, maize and millet) comprise nearly $80 \%$ of the total national cereal production (Gautam and Regmi 2013). Although the summer monsoon dominates the total precipitation in Nepal, the winter precipitation, which contributes $3 \%$ of total annual precipitation, is still important for agricultural production (Sigdel and Ikeda 2012).

There have been many studies of drought around the world, but very few in Nepal. Previous studies in Nepal have focused on the spatial pattern and temporal progression of drought events and its linkages between some climate indices and atmospheric circulation pattern (Kafle 2014; Sigdel and Ikeda 2010; Wang et al. 2013), and for annual seasonal periods. There has been no investigation for the period of crop growing seasons. Understanding and predicting the trends of droughts and using this knowledge could be helpful to support drought risk management and develop effective mitigation strategies. This paper, therefore, aims to provide a comprehensive analysis of drought phenomenon in central Nepal using Standardized Precipitation Index (SPI) computed at different time scales: 3 and 12 months year-round, and for the monsoon (4-month SPI, June to September) and winter (3-month SPI, December-February) seasons. Although these 3- and 4-month SPI are more applicable for the agricultural and 12-month SPI for hydrological aspect, some part of the lower belt of central Nepal consist of irrigated agriculture land that depends on river water for irrigation; therefore, 12-month SPI has also been calculated to assess the year round drought in central Nepal. 


\section{Materials and methods}

\subsection{Study area}

Most of the area of central Nepal is occupies by Gandaki River Basin (GRB). GRB is characterized by the highest river outflow and population (Fig. 1) compared to other river basins in Nepal. It drains an area of $32,104 \mathrm{~km}^{2}$ in Nepal. The Gandaki river network comprises 7 major tributaries. The catchment area ranges in altitude from $89 \mathrm{~m}$ above sea level in the southern lowland region (Terai) to over 8100 meters in the high Northern Himalaya. It covers the entirety of 12 districts and parts of 7 districts out of the 75 districts in Nepal.

Agriculture is the main occupation of people in GRB. Around $40 \%$ of the land of GRB is covered by agricultural land. Most of the agricultural land is rain-fed and only few irrigated croplands are present in the lowlands. Paddy rice, wheat, maize and millet are the main cereal crops grown in GRB. Paddy and wheat are the major cereal crops in the Terai region, while maize is the main crop in the Hill and Mountain regions. After maize, millet is grown in the marginal land having low productivity in the Hill and Mountain. Livestock rearing is widespread in the GRB. Depending on elevation, livestock type and concentration vary. The major livestock in the lower belt are cattle, buffaloes, goat, sheep, pigs and poultry and at higher elevation the important livestock are yak, chauris (cross between yak and local hill cow), cattle and sheep.

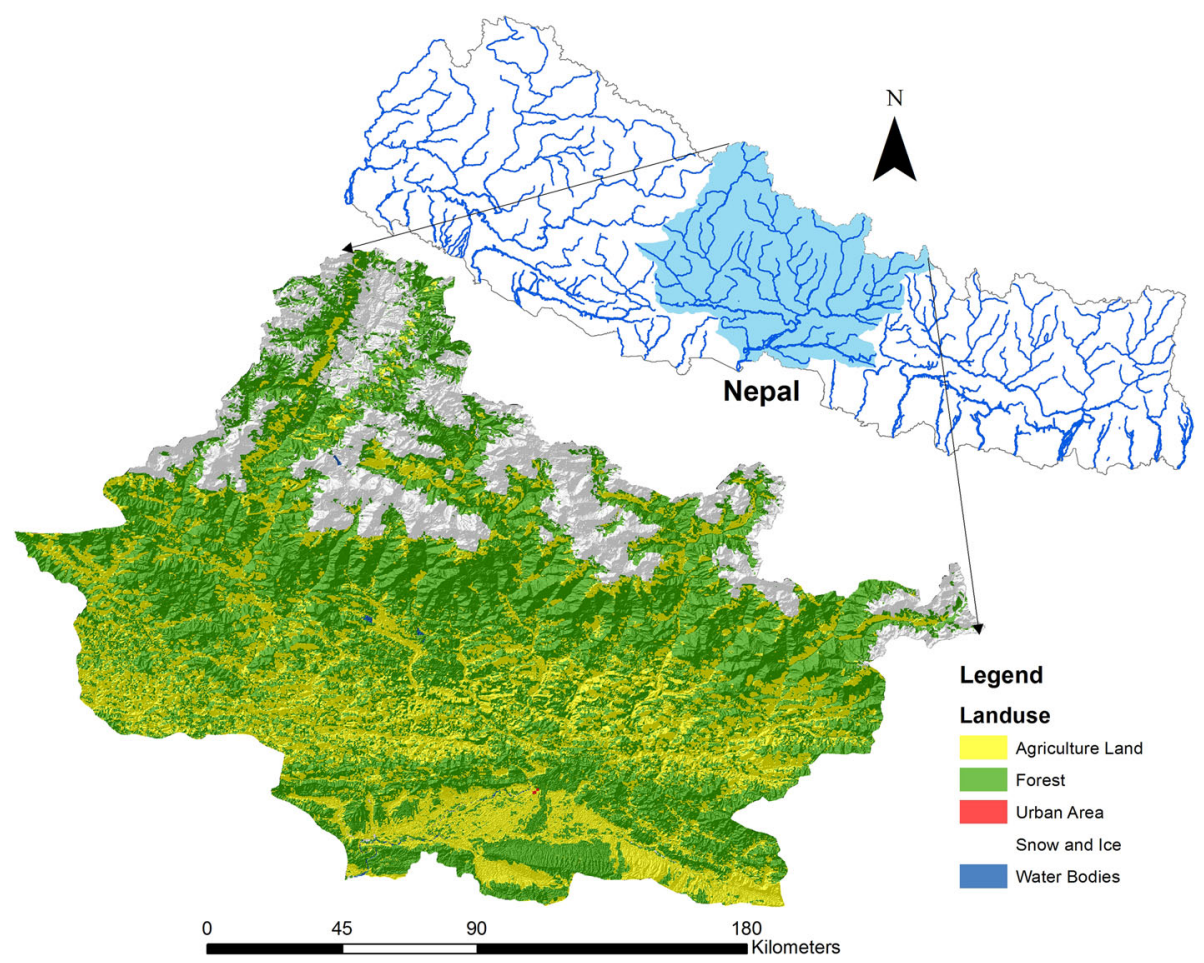

Fig. 1 Map of study area 
According to the 2011 national census, the population of GRB is 5,131,932 (19.37\% of the total population of Nepal) living in 1,172,558 households. The Terai area is densely populated whereas the Hill and High Mountain areas are sparsely populated.

\subsection{Data}

Monthly observed precipitation data for 32 years (1981-2012) obtained from the Department of Hydrology and Meteorology (DHM), Government of Nepal were used for this study. Forty precipitation stations over central Nepal (in and around GRB) were selected based on percentage of missing records less than $10 \%$. To fill missing data up to 2004, we used gridded precipitation data at $0.05^{\circ}$ spatial resolution produced over Nepal by Asian Precipitation-Highly Resolved Observational Data Integration Towards Evaluation (APHRODITE) of Water Resources project (Yatagai et al. 2012) for the period 1961-2004. We first calculated the average monthly bias of APHRODITE data with the station observations and filled the missing data from APHRODITE data after bias correction. Among 40 selected stations, 33 stations have no bias for all months. For the few missing data after 2004, we did spatial interpolation using the Kriging method on Surfer software (Version 10, http://www.goldensoftware.com/products/surfer) to impute the missing values.

\subsection{Calculation of the drought index}

The Standardized Precipitation Index (SPI) designed by McKee et al. (1993) is used to quantify drought in central Nepal. SPI is widely used around the world for drought forecasting, frequency analysis, spatio-temporal analysis and climate impact studies (Mishra and Singh 2010). SPI is also recommended as a meteorological drought index by the World Meteorological Organization (Hayes et al. 2011). In this study, the SPI was calculated on 3-, 4- and 12-month time scales, which correspond to the past 3, 4, 12 months of observed precipitation totals, respectively. SPI calculated for September on 4-month time scale is used to analyze monsoon drought, and SPI calculated for February on 3-month time scale is used to analyze winter drought over central Nepal. In this study, the procedures described in Standardized Precipitation Index: User Guide (2012) to compute the SPI on Windows 7 environments were followed.

To compute SPI, the rainfall record at a desired station is fitted to a probability distribution, which is then transformed to a normal distribution so that the mean SPI is zero (Edwards and McKee 1997). If $x$ is a precipitation data series of a desired time scale, then its probability density function satisfying gamma distribution is

$$
f(x)=\frac{1}{\beta^{\alpha} \Gamma(\alpha)} x^{a-1} e^{-x / \beta}, \quad x>0
$$

Here $\alpha$ and $\beta$ stand for shape and scale parameters, respectively.

The shape and scale parameters are estimate through the maximum likelihood method and integrating probability density function with respect to $x$ and inserting the estimated values of $a$ and $b$, the gamma cumulative distribution function (cdf) is computed at each value of $x$. The cdf is then transformed into the standard normal distribution to yield SPI. 


\subsection{Trend detection abrupt point analysis}

Mann-Kendall test (MK test) was applied to assess trends in the time series data (Kendall 1975; Mann 1945). This method has been used by many researchers for trend detection due to its robustness for non-normally distributed data (Gilbert 1987; Yue et al. 2002; Yue and Wang 2002), which are frequently encountered in hydro-climatic time series. MK test was done using the Kendall package (McLeod 2011) for R software (R Core Team 2014).

The MK test statistic $S$ is calculated as

$$
S=\sum_{j=1}^{n-1} \sum_{k=j+1}^{n} \operatorname{sgn}\left(x_{\mathrm{k}}-x_{\mathrm{j}}\right)
$$

where $x_{\mathrm{j}}$ and $x_{\mathrm{k}}$ are time series value of the $j$ th and $k$ th years $(k>j)$ and $n$ is the length of time series. The $\operatorname{sgn}\left(x_{\mathrm{k}}-x_{\mathrm{j}}\right)$ is sign function

$$
\operatorname{sgn}\left(x_{\mathrm{k}}-x_{\mathrm{j}}\right)= \begin{cases}1, & x_{\mathrm{k}}-x_{\mathrm{j}}>0 \\ 0, & x_{\mathrm{k}}-x_{\mathrm{j}}=0 \\ -1 & x_{\mathrm{k}}-x_{\mathrm{j}}<0\end{cases}
$$

the standard normal test statistic $Z_{S}$ is computed as:

$$
Z_{S}= \begin{cases}\frac{S-1}{\sqrt{\operatorname{Var}(S)}}, & S>0 \\ 0, & S=0 \\ \frac{S+1}{\sqrt{\operatorname{Var}(S)}}, & S<0\end{cases}
$$

where $\operatorname{Var}(S)$ is the variance of $S$. A positive $Z_{S}$ indicates a rising trend and vice versa.

Also, the Sequential Mann-Kendall test as described by Sneyers (1990) was used to identify the abrupt points of precipitation series. This method includes construction of a rank series of precipitation data and calculates a progressive and a retrograde series of Kendall normalized tau's. Points where the two lines cross are considered as approximate potential trend turning points.

\subsection{Spatial patterns of SPI by principal component analysis (PCA)}

To analyze the spatial patterns of covariability of SPI at different locations, Principal Component Analysis (PCA) was used. PCA generates a set of linearly independent spatial patterns (loadings) and reduces the original intercorrelated variables to a small number of new linearly uncorrelated ones which explain most of the total variance and display the spatial variability in terms of statistically deduced spatial modes (Abdi and Williams 2010). PCA involves applying a linear transformation to project data onto a new space which consists of orthonormal eigenvectors of a covariance matrix of the data called principal components. They are selected to maximize the variance of the transformed variables so that the first component contain the largest variance any linear combination can have and the $i$ th has the largest variance among linear combinations orthogonal to the first $(i-1)$ components. Extraction of the first several principal components that account for the majority of the variance of the transformed variances enables identification of the major spatial patterns and temporal modes in a high-dimensional data set. PCA was computed with the 'Stats' package in R (R Core Team 2014). 


\section{Results}

\subsection{Spatial and temporal analysis of regional precipitation}

Spatial variation of the average annual precipitation based on precipitation observation from 40 stations of GRB from 1981 to 2012 is shown in Fig. 2. There is large spatial variation in precipitation over central Nepal. Average annual precipitation ranges from less than $200 \mathrm{~mm}$ in Trans Himalayan region to more than $4000 \mathrm{~mm}$ in Middle Mountain. There is low precipitation at higher Himalaya compared to Middle Mountain and Terai.

The time series of annual, monsoon and winter precipitation of central Nepal during 1981-2012 are shown in Fig. 3. The average annual precipitation of the region is $1991.9 \mathrm{~mm}$ with a maximum of $2328 \mathrm{~mm}$ and minimum of $1492 \mathrm{~mm}$. Average regional precipitations for the monsoon and winter seasons are 1598 and $67 \mathrm{~mm}$, respectively. This shows that monsoon precipitation in the region is $80.22 \%$ of total annual precipitation. The regional average annual precipitation and monsoon precipitation do not show any trend, whereas the winter precipitation shows negative trend but not significant.

Time series information of average precipitation of any river basin is helpful to develop effective water management strategies at river basin level. But, since, Fig. 2 shows that there is large spatial variation on rainfall in central Nepal, it is also important to understand the distribution of precipitation and its trend in different sub regional context separately. Therefore we also calculate the trend of precipitation of all 40 stations separately and group them with physiographical zone of Nepal. Figure 4 shows the single-site trend analysis for precipitation. It shows that there is decreasing trend of precipitation at higher Himalaya but not distinct trend in other physiographical zones. But from this result we may also conclude that wet areas tend to have an increasing trend of precipitation, while dry areas have decreasing trend of precipitation in central Nepal.

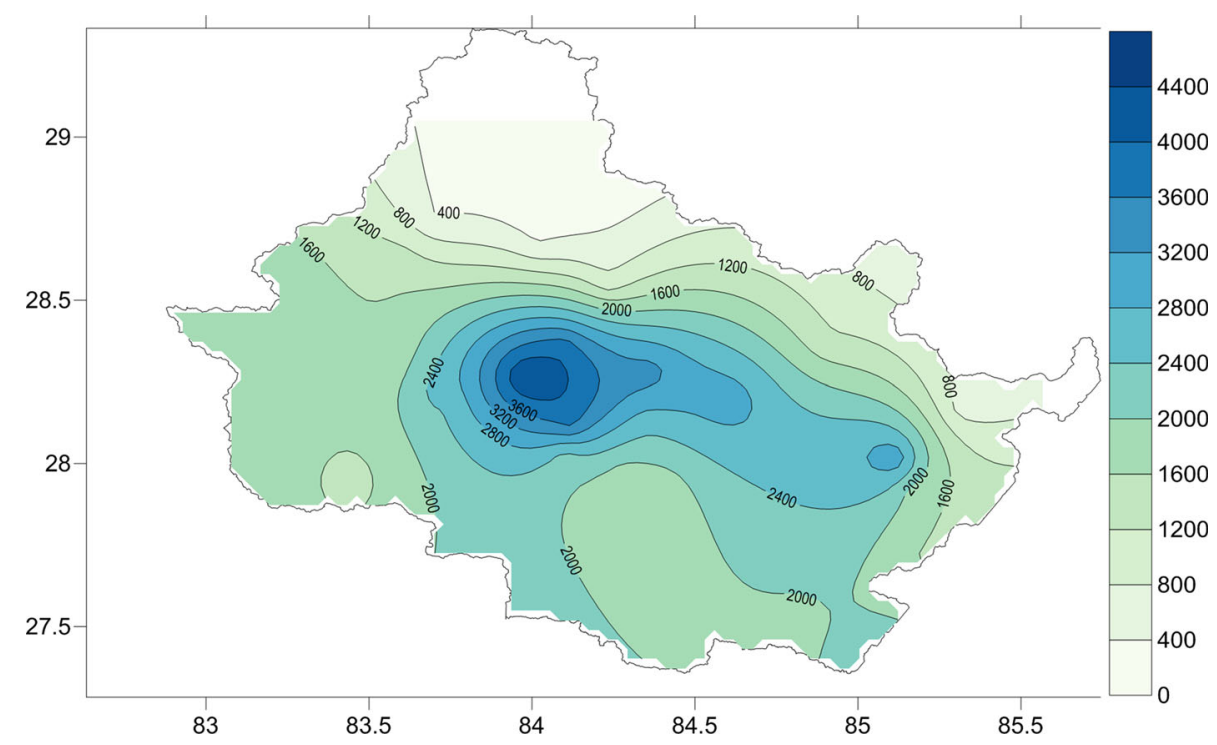

Fig. 2 Spatial distribution of the average annual precipitation ( $\mathrm{mm}$ ) based on 40 station observation from 1981 to 2012 in central Nepal 

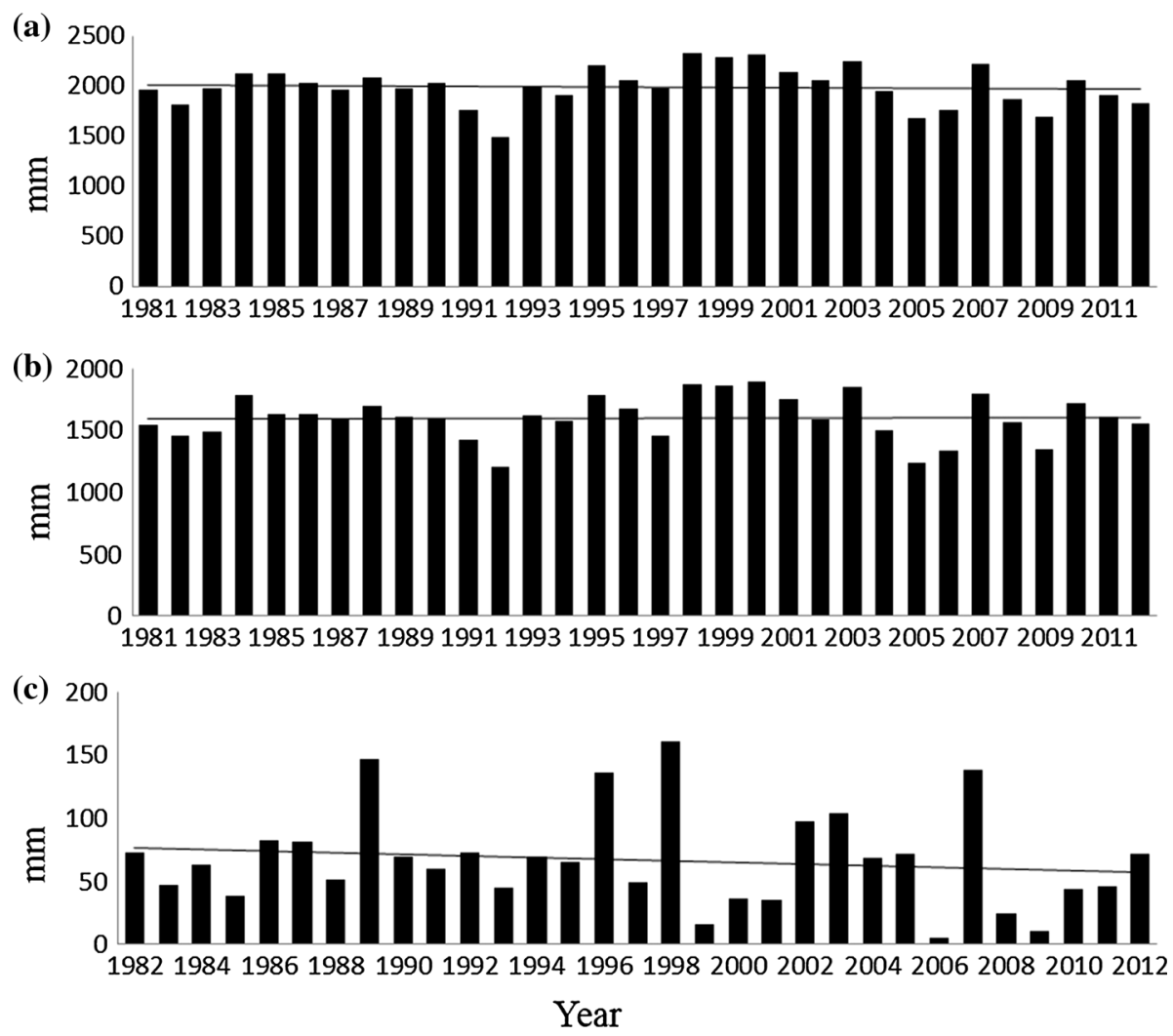

Fig. 3 Time series of regional mean precipitation a annual, b monsoon (June-September) and c winter (December-February) in central Nepal from 1981 to 2012. Solid lines denote Sen's slope trends

Trend of regional monthly precipitation was also analyzed, and it revealed that there is significantly decreasing trend of precipitation at $95 \%$ confidence interval in November and December.

\subsection{Interannual variation and abrupt change of precipitation}

Even where is no clear significant trend in precipitation in central Nepal, there is substantial interannual variation. Figure 5 shows the year-to-year variation of departure of precipitation from its mean for annual, monsoon and winter precipitation. Precipitation of an individual year is considered as excess when it is more than 1 standard deviation above the mean precipitation and deficient when it is less than 1 standard deviation below the mean precipitation (Shrestha 2000). Applying these criteria, the years 1998, 1999, 2000, 2003 and 2007 are excess rainfall years and 1991, 1992, 2005, 2006 and 2009 are rainfall deficient years in case of the annual precipitation. The excess and deficient years, case of the monsoon precipitation are similar to annual precipitation. For winter season the results are different, with 1989, 1996, 1998 and 2007 as excess rainfall years and 1999, 2006, 2008 and 2009 as deficient winter rainfall years over central Nepal. 


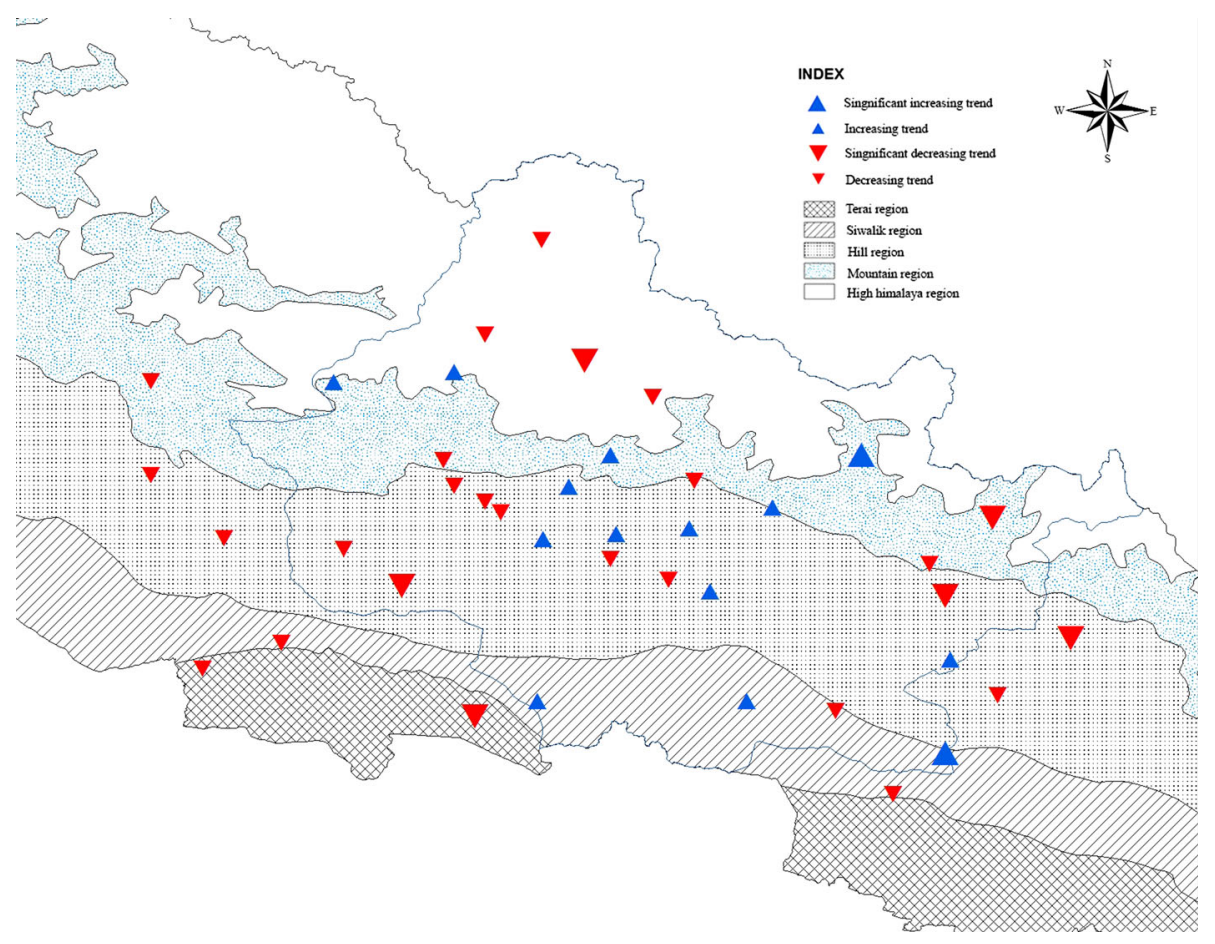

Fig. 4 Spatial variation of single-site trend for annual precipitation in central Nepal

Sequential Mann-Kendall test was applied to investigate the abrupt changes of precipitation for annual total precipitation, monsoon precipitation and winter precipitation, and result shows 4 coincidental abrupt changes for annual precipitation and monsoon precipitation around 1984, 1990, 2000 and 2009 (Fig. 6).

\subsection{Trend analysis of drought}

The results of the single-site trend analysis for SPI are shown in Fig. 7. Red triangles facing downward and blue triangles facing upward represent decreasing and increasing trends of SPI, respectively, where solid triangles indicate significant trends. It shows that significant trends are mostly negative and they tend to prevail for the 12-month time scale. This reveals a clear tendency toward drought over central Nepal in past decades. For the 12-month time scale, $65 \%$ (26 out of 40) stations have increasing trend of drought and out of these 20 have significant trend. Three-month drought trend also follows a similar pattern. Winter drought (3-month SPI at February) shows increasing trend of drought for $90 \%$ of stations, but only 1 of them is significant and for monsoon drought (4-month SPI at September), 23 stations show increasing trend of drought and 4 of them are significant. Clear spatial patterns are difficult to identify, but there is increasing trend of drought on high Himalaya and in the western part even at low altitudes for all time scales. Also the areas having high annual precipitation have decreasing trends in drought, while areas having low annual precipitation have increasing trend of drought for all time scales. This 

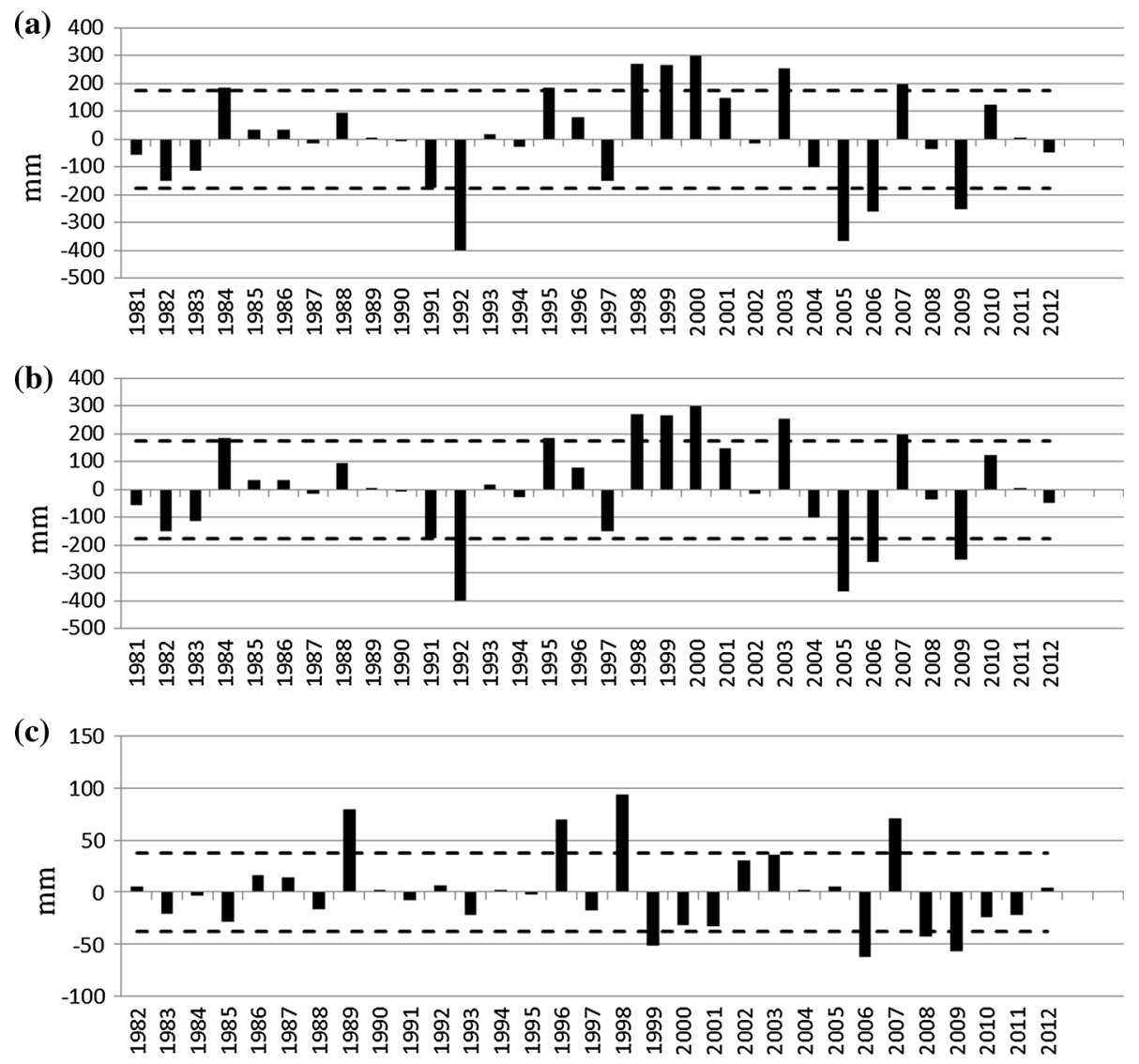

Year

Fig. 5 Variation of departure of precipitation from mean for a annual, $\mathbf{b}$ monsoon, $\mathbf{c}$ winter precipitation over central Nepal. Dashed lines mark \pm 1 standard deviation

again implies a situation where wet areas are becoming wetter and dry areas are becoming drier in central Nepal.

\subsection{Spatial pattern of drought}

For the spatial pattern of drought, the number of PCs to retain was determined according to the cumulative proportion of variance explained by PCs. Table 1 summarizes the percentage of variance explained by the first 10 components for the SPI for each time scale.

For 12-month time scale, 8 components explained $70 \%$ of total variance of the SPI series. Also, the same number of components and a similar percentage of variance were explained for a 4-month time scale calculated in September for Monsoon drought. For 3-month time scale, the number of components increased to 10 and for 3-month time scale calculated in February for winter drought it decreased to 2 to explain the $70 \%$ of total variance. This observation shows a distribution of total variance among a fairly large number of components selected except for winter. This indicates that the winter drought is 
(a)

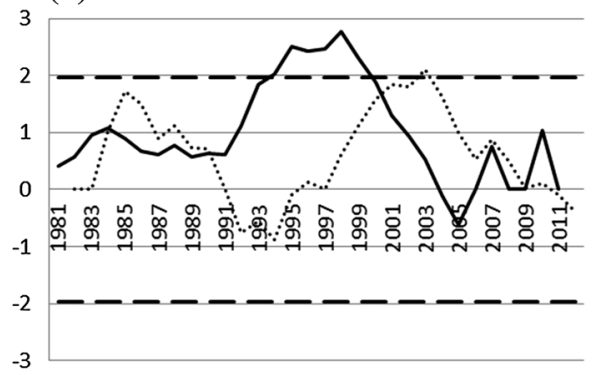

(b)

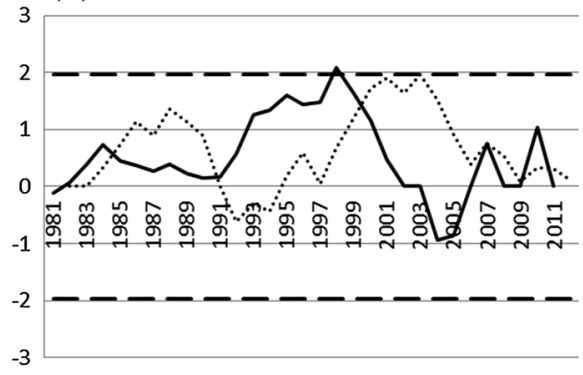

(c)

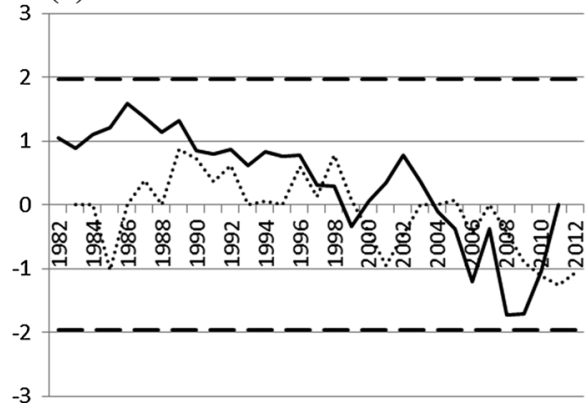

Fig. 6 Analysis of abrupt changes in precipitation by Sequential MK test for a annual, b monsoon and c winter. Solid line represents progressive and dot line represents retrograde series of Kendall normalized tau's and the dashed line gives the confidence level $(P=0.05)$. The crosspoints of progressive and retrograde are the start points of the abrupt changes in the series

Table 1 Variance contributions (\%) of the first 10 components for SPI at different time scales

\begin{tabular}{lllllllllll}
\hline PCAs & F1 & F2 & F3 & F4 & F5 & F6 & F7 & F8 & F9 & F10 \\
\hline SPI_12 & 28.473 & 8.637 & 8.149 & 6.157 & 5.851 & 4.791 & 4.506 & 4.066 & 3.487 & 3.080 \\
SPI_3 & 39.307 & 5.607 & 4.582 & 4.015 & 3.726 & 3.347 & 2.870 & 2.619 & 2.473 & 2.199 \\
SPI_monsoon & 28.259 & 8.918 & 8.261 & 6.793 & 6.268 & 5.822 & 4.173 & 3.746 & 3.467 & 3.187 \\
SPI_winter & 67.719 & 4.059 & 3.673 & 3.429 & 2.917 & 2.391 & 1.854 & 1.746 & 1.597 & 1.448 \\
\hline
\end{tabular}

characterized by two very clear patterns and but for other time scale there is a complex spatial pattern of drought.

The spatial patterns of the factorial loadings obtained from first three PCAs for each time scale are presented in Fig. 8.

For SPI_12, the first principal component PC1, which explains about $28.47 \%$ of the variance, has strong positive loadings at central area and has good correlation with more than half of the region. Second and third PCs shows large variation, and most of the area has very low correlation with respective factor loadings. For SPI_3, around $60 \%$ of the area has strong positive loadings of PC1 and loadings of PC2 and PC3 have low correlation on most of the area. SPI_monsoon has a spatial pattern of loading quite similar to SPI_12, but the central area with very strong positive PC1 loading shifts toward the west. For SPI_winter, more than $70 \%$ of the area has high correlation $(>0.6)$ with PC1 loadings. 

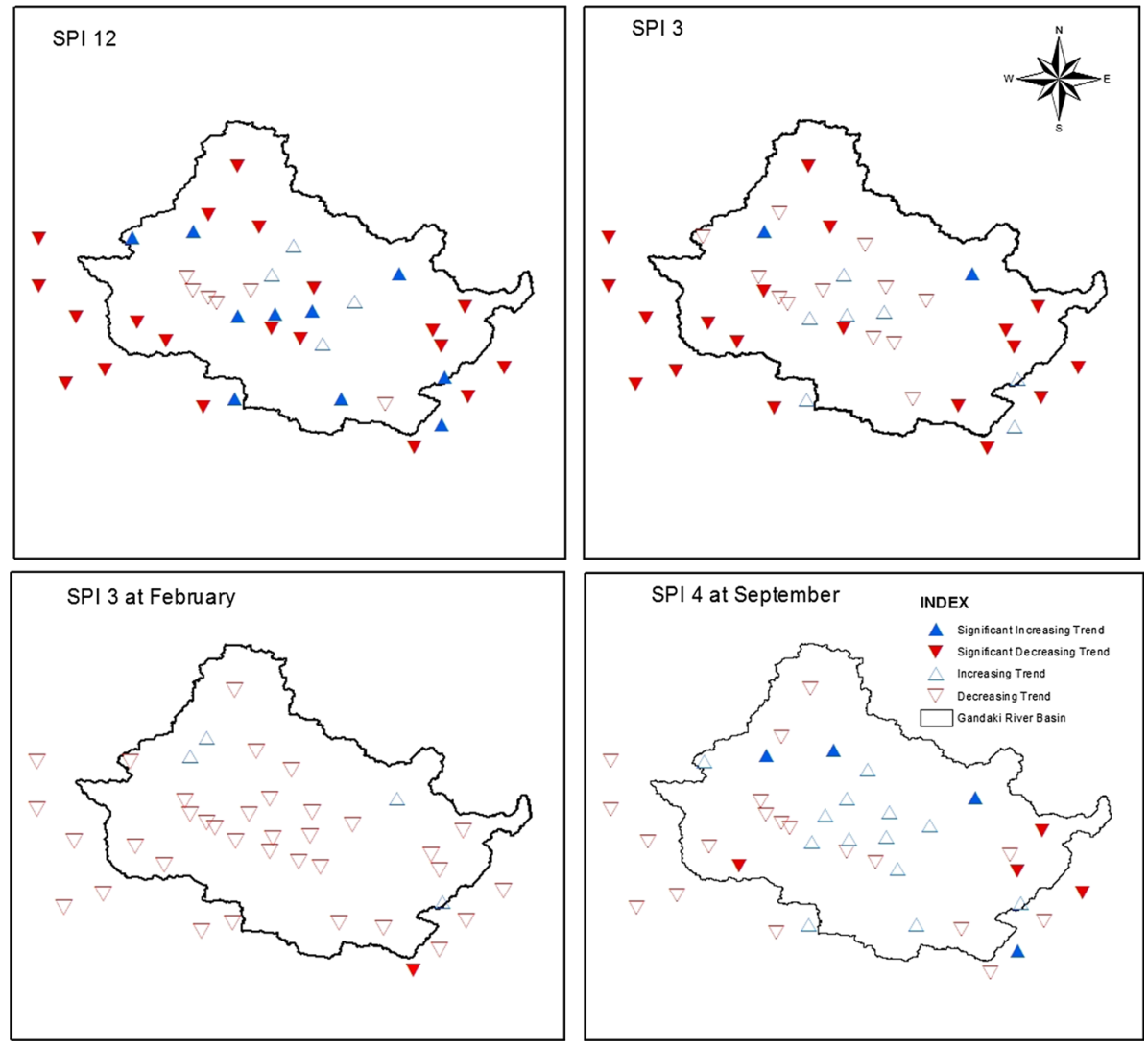

Fig. 7 Spatial variation of single-site trend for SPI at different time scales

Only the few highest stations have correlations below 0.4 . This clearly demonstrates that there is relatively uniform behavior of winter drought across central Nepal.

\subsection{Seasonal drought frequency and spatial extent of intensity in recent years}

Drought occurrences in monsoon and winter seasons in different years (defined as SPI $<-1$ ) are depicted in Fig. 9. Figure 9 shows both monsoon and winter droughts were recorded in more stations since the late 1990s, thus indicating a spread of drought in large parts of central Nepal. More than $90 \%$ of stations recorded drought during the winter season of year 2006 and 2009. The next most widespread winter droughts were for 1999 and 2008 (50-60\% of stations). More than $30 \%$ of the stations recorded drought during monsoon season of year 2004, 2005, 2006 and 2009.

Spatial extent of droughts for the recent years 2011 and 2012, in both monsoon and winter seasons is mapped on Figs. 10 and 11. Monsoon drought has occurred on some part of central Nepal on all years expect 2001. Drought occurred with large spatial extent mainly in the summer season of year 2005, 2009, 2006 and 2004 among which 2005 experienced drought in largest spatial area. For the winter seasons, the worst droughts occurred in the years 2006 and 2009 and have been experienced by almost all areas of the 

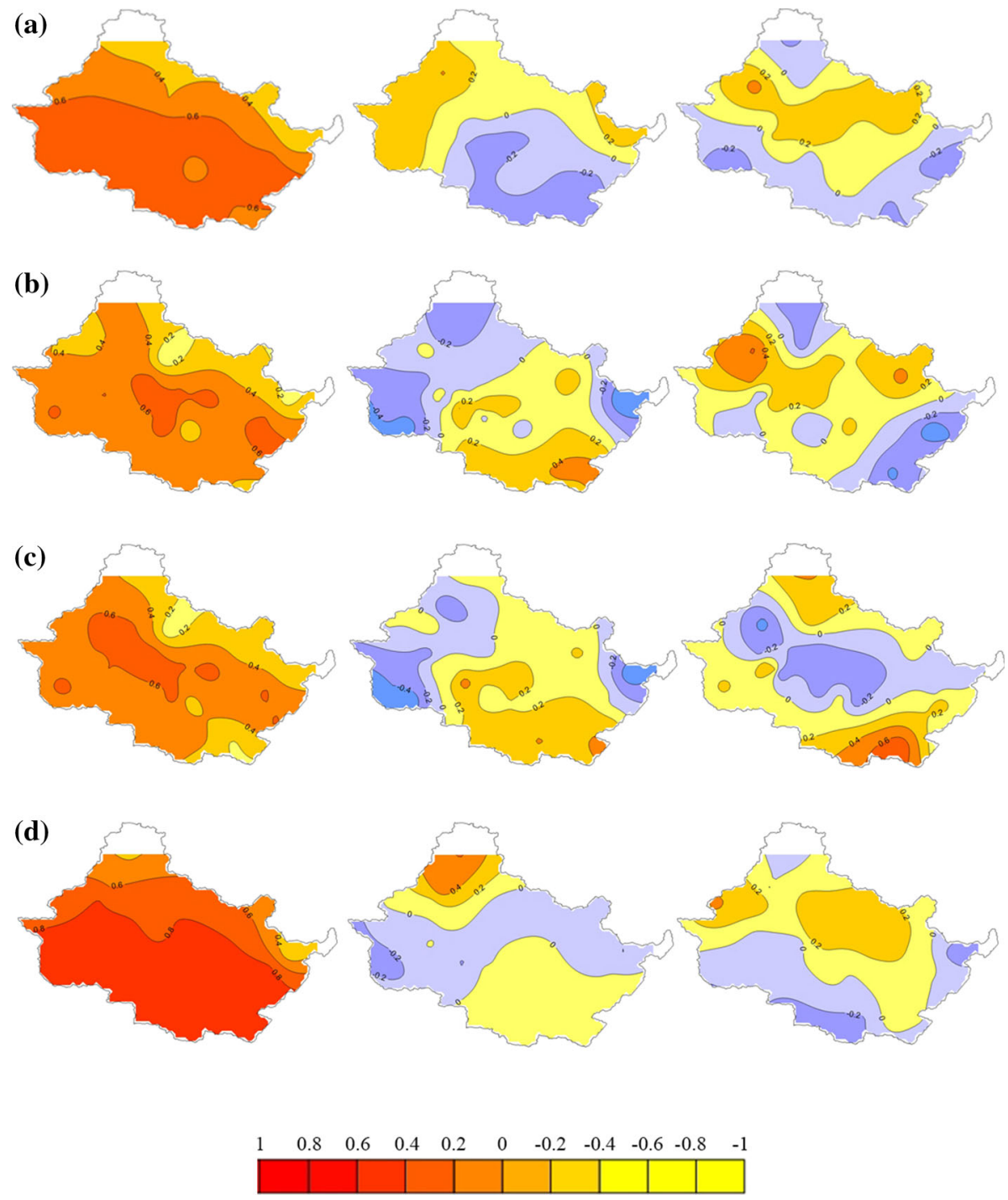

Fig. 8 Loading patterns of the first three principle component components (PCs) for a SPI_12, b SPI_3, c SPI_Monsoon and d SPI_Winter

central Nepal. 2008 was another winter drought year where a large spatial area was covered by drought.

\section{Discussion}

This paper evaluates drought during major crop growing seasons in central Nepal. For this, the temporal and spatial patterns of regional precipitation and droughts in the central Nepal for the period 1981-2012 were analyzed. Distinct long-term trends were not found on 


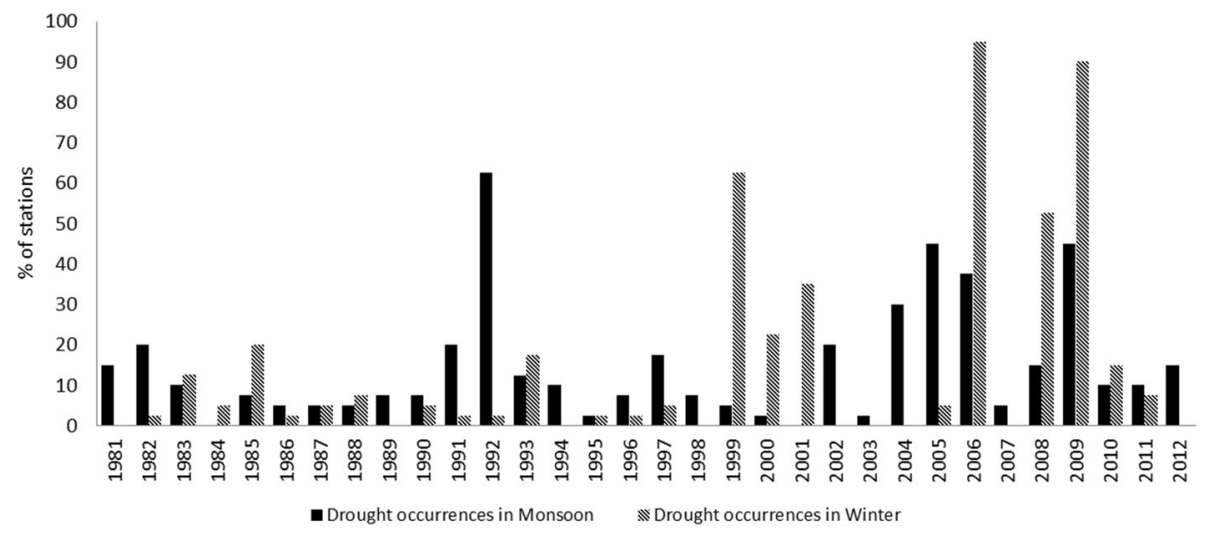

Fig. 9 Drought occurrence in monsoon and winter season

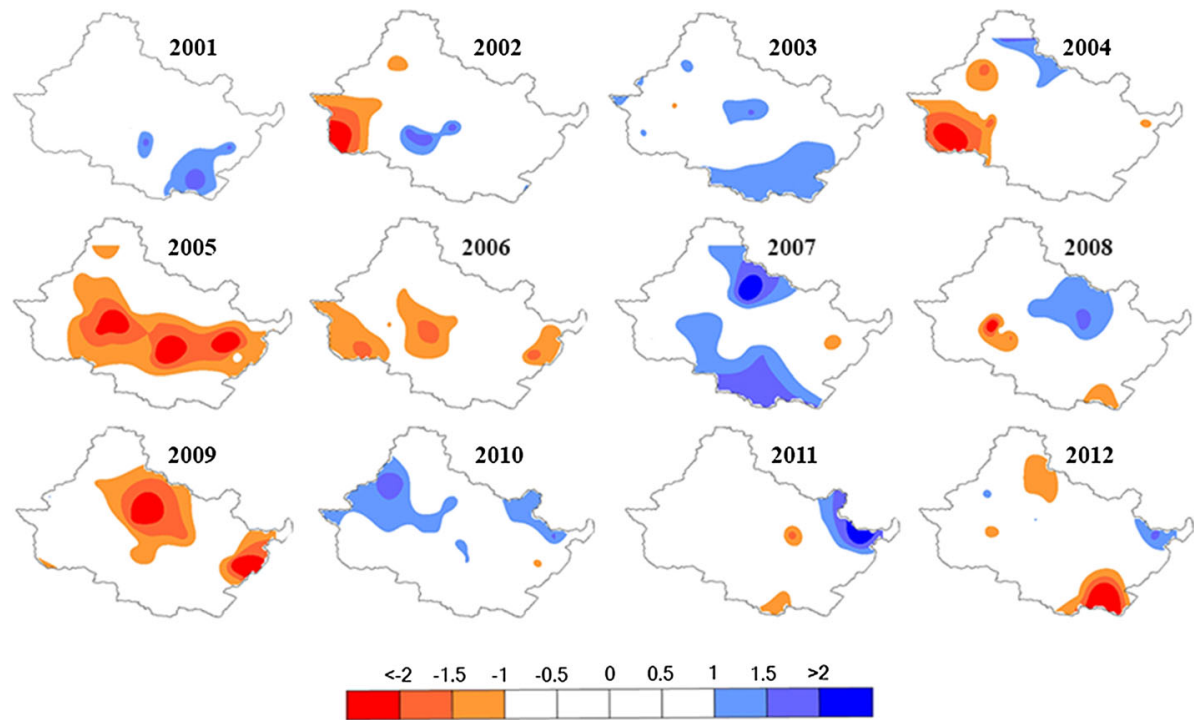

Fig. 10 Spatial distribution of SPI for monsoon season in recent years (2001-2012) over central Nepal

precipitation records for annual mean and monsoon and winter season, but large interannual variations were present. In winter this region experiences subtropical westerly jetstream in the upper troposphere and these occasionally brings cold spells and rain. Therefore there is large inter annual variation on winter precipitation in this region (Nayava 1980). The years 1991, 1992, 2005, 2006 and 2009 are found to be rainfall deficient years. The regional precipitation trend agrees well with the analysis of precipitation records from this region and all Nepal by Panthi et al. (2015a), Krakauer et al. (2013), Shrestha and Aryal (2010) and Shrestha (2000). Since the areas that receive highest amount of rainfall in the country and lowest amount of rainfall in the country lie in the study area, there is large spatial variation of precipitation. The annual precipitation patterns show a region of high values toward the center of the region, i.e., southern foothills of the 

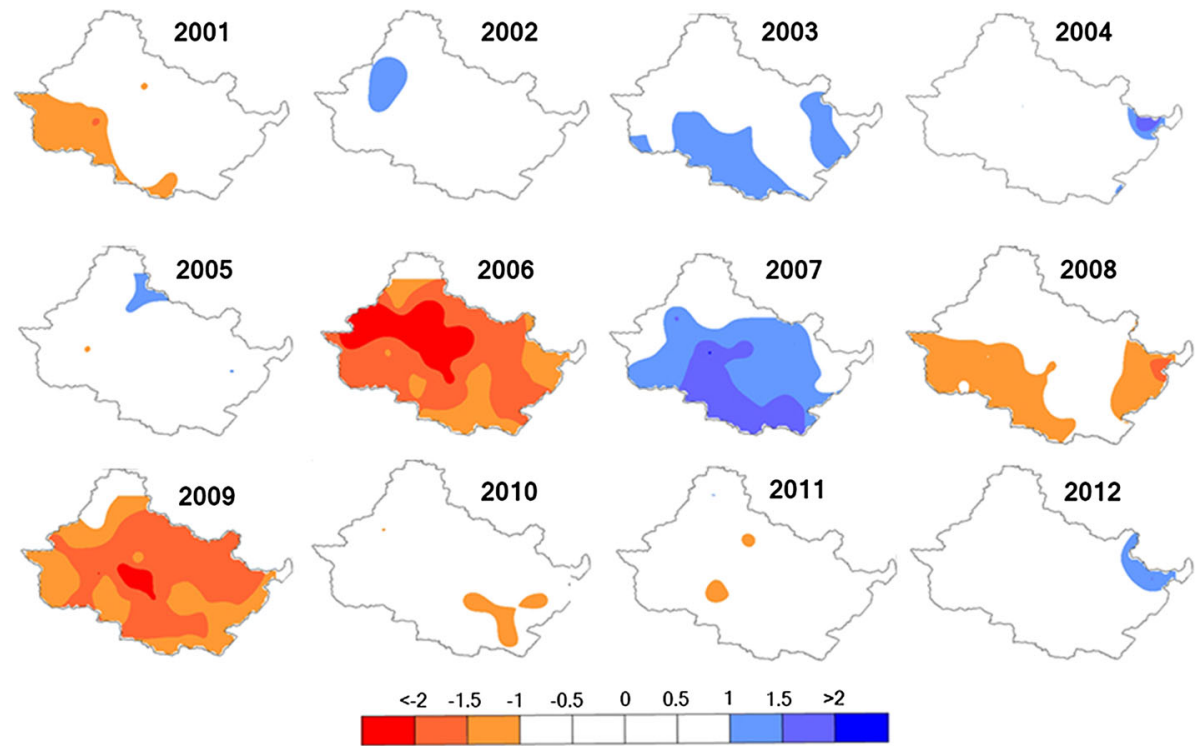

Fig. 11 Spatial distribution of SPI for winter season in recent years (2001-2012) over central Nepal

Himalayas, and low value toward northern part of the Himalayas. The spatial variations are controlled mostly by the topographical features of this Himalayan range (Shrestha 2000). But the notable finding is that the wet areas have increasing trend of precipitation and dry areas have decreasing trend of precipitation in the central Nepal. Aryal et al. (2014) state that upper Mustang region, the driest part of the basin, has been experiencing the reduction in the area of land suitable for agriculture due to decreasing precipitation. Recently, in 2013 Dhe village of upper Mustang had experienced a severe drought, where almost all the households had to be relocated due to acute shortage of water for drinking and irrigation caused by decreasing precipitation and prolonged drought over the last 6-7 years (Khatri 2013). Another notable finding is that the driest months for region, November and December, have significant decreasing trend of precipitation at $5 \%$ level of significance.

The trend analysis of SPI magnitude showed a decreasing tendency, indicating increasing drought, which is more evident at the longer time scale. Even there is limited study concerning drought trend in Nepal, evidence of increased occurrence of drought due to precipitation deficit is consistent with the results presented by previous researchers (Kafle 2014; Sigdel and Ikeda 2010; Wang et al. 2013) as summarized above. The analysis of SPI could be an effective tool in identifying the drought trends. Our results indicate that both drought frequency and intensity have increased in recent years. Drought occurred on large spatial extent mainly on the summer season of the years 2004, 2005, 2006 and 2009 and winter droughts occurred in the years 2006, 2008 and 2009, which are the worst of the period since 1981 and were experienced by almost all areas of central Nepal. This evolution toward drier conditions is consistent with the results of the analyses of drought done in different parts of Nepal.

Several studies (Chang and Kleopa 1991; Heim 2002; Paulo and Pereira 2006) have shown that precipitation is the main variable determining drought condition; however, many empirical studies (Hu and Willson 2000; Rebetez et al. 2006; Vicente-Serrano et al. 2009) 


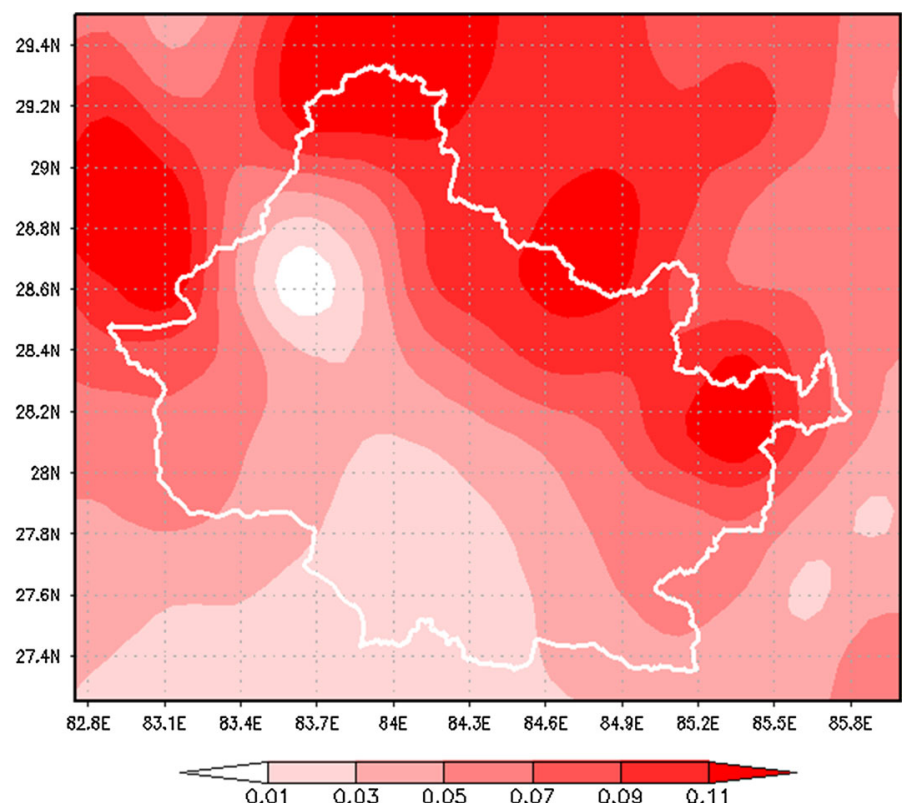

Fig. 12 Rate of change of temperature (degree Celsius per year) in central Nepal during 1981-2007 (Data source: gridded temperature data sets by Asian precipitation-highly resolved observational data integration toward evaluation of water resources (APHRODITE's water resources) http://www.chikyu.ac.jp/precip/ index.html)

have shown that rise in temperature has important effects on the severity of droughts conditions. Figure 12 shows that there is increasing trend of temperature in all region of central Nepal in past. This indicates that there may have great consequences for drought conditions, with an increase in water demand as a result of evapotranspiration in this region.

There is a lot of evidence that these dry periods have a serious impact on agriculture production (2008/09 Winter Drought in Nepal-Crop and Food Security Assessment 2009; Gentle and Maraseni 2012; Ghimire et al. 2010; Wang et al. 2013). Wang et al. (2013) state that the severe winter drought experienced in 2008-2009 in Western Nepal was unprecedented in both scale and severity and receive less than $50 \%$ of the average precipitation for the period November 2008 to February 2009. In 2009, production of wheat and barley, which are the two major winter crops, had decreased about $50 \%$ in comparison with the previous year and $66 \%$ of rural households experienced food shortages, with the worst hit areas in the Far- and Mid-Western Hill and Mountain districts (mostly west of GRB study region). This constituted a record low decrease in production and had created a record annual deficit in supply versus demand in Nepal (2008/09 Winter Drought in NepalCrop and Food Security Assessment 2009). During the same period, mountain communities of Nepal also reported that decreasing and erratic rainfall patterns and drought are the most serious hazard for agriculture, causing decreasing food production and crop failure. A livelihood vulnerability assessment in the GRB found that, due to limited adaptive capacity and greater climate variability, rural people in the mountain zone were more vulnerable than those in the lowland and hill zones (Panthi et al. 2015b). Poor households without irrigated land were found to be facing greater risks and stresses due to 
(a)

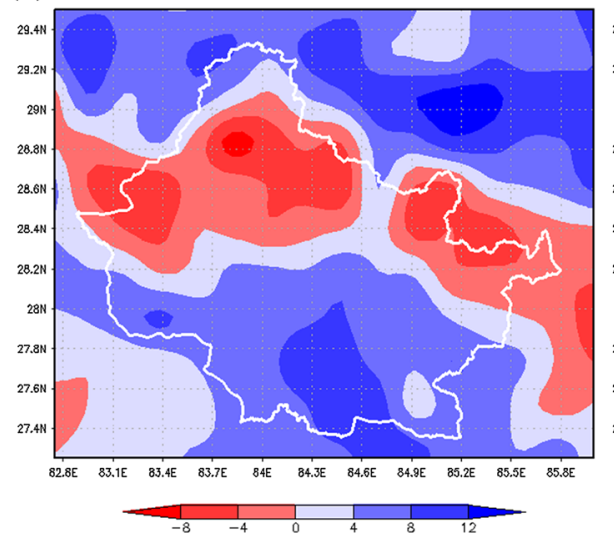

(b)

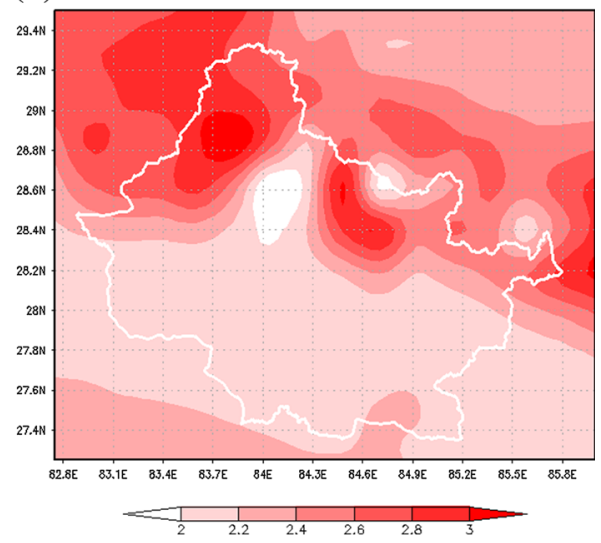

Fig. 13 Projected change in a precipitation (in \%) and b temperature (in ${ }^{\circ} \mathbf{C}$ ) for 2031-2060 compared to the baseline period 1970-2000 in central Nepal obtained from downscaling the data of HadCM3Q0 global model by PRECIS regional climate model. Data source: Department of Hydrology and Meteorology, Government of Nepal

these prolonged droughts than well-off people (Gentle and Maraseni 2012). Also, the long dry spell of the 2005/06 winter particularly affected subsistence hill and mountain farmers in the Mid- and Far-Western regions. The winter rainfall was less than $30 \%$ of normal with some areas receiving no precipitation. During fiscal year 2005/06, food production was adversely affected by drought with reported decrease in the average paddy and wheat production. Overall paddy production decreased by $12.55 \%$ compared to previous year and in some districts of the Eastern and Central regions, reduction was from 20 to $50 \%$. A total of 42 out of the 75 districts experienced food-deficit in 2006/07 (Regmi 2007; Special Report-FAO/WFP Food Security Assessment Mission to Nepal 2007).

Since drought phenomenon largely depends on precipitation amount and surface temperature which greatly affect evapotranspiration and water stress. Figure 13 shows future projected change in temperature and precipitation obtained from downscaling the data of HadCM3Q0 global model by PRECIS regional climate model. The result shows that precipitation in central Nepal will change by -8 to $12 \%$ and temperature will change by 1.9-3 ${ }^{\circ} \mathrm{C}$ in 2031-2060 compared to the baseline period 1970-2000. Since there will be increase in temperature while much of the drier high altitude region in central Nepal may experience decreasing rainfall, we can predict that there will be increasing drought condition in higher altitude of central Nepal which is already dry. Since large parts of central Nepal may face an increasing risk of drought in future due to climate change and the country's policies have not paid adequate attention to climate vulnerability in the agriculture sector (Pradhanang et al. 2015), there is an urgent need for formulating policy that addresses adaptation to likely future droughts.

\section{Conclusions}

There were no significant distinct trends of precipitation for mean annual, monsoon and winter rainfall of the central Nepal, but there is large interannual variation. The years 1991, 1992, 2005, 2006 and 2009 are found to be rainfall deficient years. Due to large 
topographical variation and the presence of the Himalaya, there is large spatial variation within the region. Although there is no overall trend in average precipitation, the area receiving large amount of precipitation showed an increasing trend of precipitation, while dry areas have decreasing trend of precipitation. Also, the driest months for Nepal, November and December, have significant decreasing trend of precipitation. Trend analysis of SPI reveals a clear tendency toward more droughts over the past decades and is more evident at the longer time scale. Both drought frequency and intensity in recent years were found to have increased. Among the drought years, summer season of year 2004, 2005, 2006, 2009 and winter of year 2006, 2008 and 2009 are the worst since 1981 and have been experienced by almost all areas of central Nepal. Other sources confirm that this drought condition has been severely affecting agricultural production in central Nepal.

Acknowledgments We are grateful to the Department of Hydrology and Meteorology, Government of Nepal for providing station precipitation data and for APHRODITE projects for creating and making available their precipitation products. This work is part of the project "Adaptation for climate change by livestock smallholders in Gandaki river basin", supported by the USAID Feed the Future Innovation Lab for Collaborative Research for Adapting Livestock Systems to Climate Change at Colorado State University under subaward 9650-32. Support was also provided by NOAA under award NA15OAR4310080. All statements made are the views of the authors and not the opinions of the funders or the US government.

Open Access This article is distributed under the terms of the Creative Commons Attribution 4.0 International License (http://creativecommons.org/licenses/by/4.0/), which permits unrestricted use, distribution, and reproduction in any medium, provided you give appropriate credit to the original author(s) and the source, provide a link to the Creative Commons license, and indicate if changes were made.

\section{References}

2008/09 Winter Drought in Nepal-Crop and Food Security Assessment (2009) Ministry of Agriculture and Cooperatives, Government of Nepal, World Food Programme, Food and Agriculture Organization of the United Nations, Kathmandu

Abdi H, Williams LJ (2010) Principal component analysis. Wiley Interdiscip Rev Comput Stat 2:433-459. doi:10.1002/wics.101

Ahmad S, Hussain Z, Qureshi AS, Majeed R, Saleem M (2004) Drought mitigation in Pakistan: current status and options for future strategies, vol 3. International Water Management Institute, Colombo

Aryal A, Brunton D, Raubenheimer D (2014) Impact of climate change on human-wildlife-ecosystem interactions in the Trans-Himalaya region of Nepal. Theory Appl Climatol 115:517-529. doi:10.1007/ s00704-013-0902-4

Below R, Grover-Kopec E, Dilley M (2007) Documenting drought-related disasters a global reassessment. J Environ Dev 16:328-344. doi:10.1177/1070496507306222

Bhalme HN, Mooley DA (1980) Large-scale droughts/floods and monsoon circulation. Mon Weather Rev 108:1197-1211. doi:10.1175/1520-0493(1980)108<1197:LSDAMC >2.0.CO;2

Byun H-R, Wilhite DA (1999) Objective quantification of drought severity and duration. J Clim 12:2747-2756. doi:10.1175/1520-0442(1999)012<2747:OQODSA $>2.0 . C O ; 2$

Chang TJ, Kleopa XA (1991) A proposed method for drought monitoring. JAWRA J Am Water Resour As 27:275-281. doi:10.1111/j.1752-1688.1991.tb03132.x

Ciais $\mathrm{P}$ et al (2005) Europe-wide reduction in primary productivity caused by the heat and drought in 2003. Nature 437:529-533. doi:10.1038/Nature03972

Climate-Resilient Planning (2011) A tool for long-term climate adaptation. National Planning Commission, Government of Nepal, Kathmandu

Dow K (2010) News coverage of drought impacts and vulnerability in the US Carolinas, 1998-2007. Nat Hazards 54:497-518. doi:10.1007/s11069-014-1215-3

Downing TE, Bakker K (2000) Drought discourse and vulnerability. Drought: a global assessment, natural hazards and disasters series. Routledge, London

Edwards DC, McKee TB (1997) Characteristics of 20th century drought in the United States at multiple time scales. Department of Atmospheric Science, Colorado State University, Colorado 
Funk C (2011) We thought trouble was coming. Nature. doi:10.1038/476007a

Gautam DK, Regmi SK (2013) Recent trends in the onset and withdrawal of summer monsoon over Nepal. ECOPERSIA 1:353-367

Gentle P, Maraseni TN (2012) Climate change, poverty and livelihoods: adaptation practices by rural mountain communities in Nepal. Environ Sci Policy 21:24-34. doi:10.1016/j.envsci.2012.03.007

Ghimire YN, Shivakotia GP, Perretb SR (2010) Household-level vulnerability to drought in hill agriculture of Nepal: implications for adaptation planning. Int J Sustain Dev World Ecol 17:225-230. doi:10.1080/ 13504501003737500

Gibbs WJ, Maher JV (1967) Rainfall deciles as drought indicators. Bureau of Meteorology Bulletin No. 48 Commonwealth of Australia, Melbourne

Gilbert RO (1987) Statistical methods for environmental pollution monitoring. Van Nostrand Reinhold, New York

Gumma MK, Gauchan D, Nelson A, Pandey S, Rala A (2011) Temporal changes in rice-growing area and their impact on livelihood over a decade: a case study of Nepal. Agric Ecosyst Environ 142:382-392. doi:10.1016/j.agee.2011.06.010

Guttman NB (1998) Comparing the Palmer drought index and the standardised precipitation index. J Am Water Res As 34:113-121

Hayes M, Svoboda M, Wall N, Widhalm M (2011) The Lincoln declaration on drought indices: universal meteorological drought index recommended. Bull Am Meteorol Soc 92:485-488

Heim RR (2002) A review of twentieth-century drought indices used in the United States. B Am Meteorol Soc 83:1149-1165

Hu Q, Willson GD (2000) Effect of temperature anomalies on the Palmer drought severity index in the central United States. Int J Climatol 20:1899-1911. doi:10.1002/1097-0088(200012)20:15<1899:: AID-JOC588>3.0.CO;2-M

Kafle HK (2014) Spatial and Temporal Variation of Drought in Far and Mid Western Regions of Nepal: Time Series Analysis (1982-2012). Nepal J Sci Technol 15:65-76

Kansakar SR, Hannah DM, Gerrard J, Rees G (2004) Spatial pattern in the precipitation regime of Nepal. Int J Climatol 24:1645-1659. doi:10.1002/joc.1098

Kendall MG (1975) Rank correlation methods. Charles Griffin, London

Khatri N (2013) Climate-change Refugees in Nepal: the need for climate-smart capacity building. In: Leal Filho W (ed) Climate change and disaster risk management. Climate change management. Springer, Berlin, pp 351-357. doi:10.1007/978-3-642-31110-9_22

Krakauer NY, Pradhanang SM, Lakhankar T, Jha AK (2013) Evaluating satellite products for precipitation estimation in mountain regions: a case study for Nepal. Remote Sens 5:4107-4123. doi:10.3390/ rs5084107

Lena BD, Vergni L, Antenucci F, Todisco F, Mannocchi F (2013) Analysis of drought in the region of Abruzzo (Central Italy) by the Standardized Precipitation Index. Theor Appl Climatol 115:41-52. doi:10.1007/s00704-013-0876-2

Liu X, Zhang J, Ma D, Bao Y, Tong Z, Liu X (2013) Dynamic risk assessment of drought disaster for maize based on integrating multi-sources data in the region of the northwest of Liaoning Province, China. Nat Hazards 65:1393-1409. doi:10.1007/s11069-012-0416-X

Liu Y-W, Wang W, Hu Y-M, Liang Z-M (2014) Drought assessment and uncertainty analysis for Dapoling basin. Nat Hazards. doi:10.1007/s11069-014-1259-4

Mann HB (1945) Nonparametric tests against trend. Econometrica 13:245-259

McKee T, Doesken N, Kleist J (1993) The relationship of drought frequency and duration to time scales. In: 8th conference on applied climatology. American Meteorological Society, Boston, pp 179-184

McLeod AI (2011) Kendall rank correlation and Mann-Kendall trend test, R package version 2.2 edn

Mishra AK, Singh VP (2010) A review of drought concepts. J Hydrol 391:202-216. doi:10.1016/j.jhydrol. 2010.07.012

Nagaraja BC, Somashekar RK, Kavitha A (2011) Impact of drought on agriculture: challenges facing poor farmers of Karnataka, south India. In: Paper presented at the climate change and security, Norway

Nayava JL (1980) Rainfall in Nepal. Himal Rev 12:1-18

Nepal Living Standards Survey 2010/11 (2011) Central Bureau of Statistics, National Planning Commission Secretariat, Government of Nepal, Kathmandu

Palmer WC (1965) Meteorological drought. U.S. Department of Commerce Weather Bureau, Washington, D.C.

Palmer WC (1968) Keeping track of crop moisture conditions, nationwide: the New Crop Moisture Index. Weatherwise 21:156-161. doi:10.1080/00431672.1968.9932814

Panthi J et al (2015a) Spatial and temporal variability of rainfall in the Gandaki river basin of Nepal Himalaya. Climate 3:210-226. doi:10.3390/cli3010210 
Panthi J, Aryal S, Dahal P, Bhandari P, Krakauer N, Pandey V (2015b) Livelihood vulnerability approach to assessing climate change impacts on mixed agro-livestock smallholders around the Gandaki River Basin in Nepal. Reg Environ Change 1-12. doi:10.1007/s10113-015-0833-y

Paulo AA, Pereira LS (2006) Drought concepts and characterization. Water Int 31:37-49. doi:10.1080/ 02508060608691913

Popova Z, Ivanova M, Martins D, Pereira LS, Doneva K, Alexandrov V, Kercheva M (2014) Vulnerability of Bulgarian agriculture to drought and climate variability with focus on rainfed maize systems. Nat Hazards. doi:10.1007/s11069-014-1215-3

Pradhanang U, Pradhanang S, Sthapit A, Krakauer N, Jha A, Lakhankar T (2015) National livestock policy of Nepal: needs and opportunities. Agriculture 5:103-131. doi:10.3390/agriculture5010103

Rebetez M, Mayer H, Dupont O, Schindler D, Gartner K, Kropp JP et al (2006) Heat and drought 2003 in Europe: a climate synthesis. Ann For Sci 63:569-577

Regmi HR (2007) Effect of unusual weather on cereal crop production and household food security. J Agric Environ 8:20-29

Rooy MPV (1965) A rainfall anomaly index independent of time and space. Notos 14:6

Rossi G, Benedini M, Tsakiris G, Giakoumakis S (1992) On regional drought estimation and analysis. Water Resour Manag 6:249-277. doi:10.1007/BF00872280

Shafer BA, Dezman LE (1982) Development of a surface water supply index (SWSI) to assess the severity of drought conditions in snowpack runoff areas. In: 50th Annual western snow conference, Reno, Nevada. Proceedings of the 50th annual western snow conference. Western Snow Conference

Shrestha ML (2000) Interannual variation of summer monsoon rainfall over Nepal and its relation to Southern Oscillation Index. Meteorol Atmos Phys 75:21-28. doi:10.1007/s007030070012

Shrestha AB, Aryal R (2010) Climate change in Nepal and its impact on Himalayan glaciers. Reg Environ Change. doi:10.1007/s10113-010-0174-9

Sigdel M, Ikeda M (2010) Spatial and temporal analysis of drought in Nepal using Standardized Precipitation Index and its relationship with climate indices. J Hydrol Meteorol 7:59-74

Sigdel M, Ikeda M (2012) Seasonal contrast in precipitation mechanisms over Nepal deduced from relationship with the large-scale climate patterns. Nepal J Sci Technol 13:115-123

Sneyers R (1990) On the statistical analysis of series of observations. World Meteorol Organ, Geneva

Special Report-FAO/WFP Food Security Assessment Mission to Nepal (2007) Food and Agriculture Organization of the United Nations. World Food Programme, Rome

Standardized Precipitation Index: User Guide (2012) World Meteorological Organization (WMO), Switzerland

Team RC (2014) R: a language and environment for statistical computing, 3.1.1 edn. R Foundation for Statistical Computing, Vienna, Austria

Trenberth KE, Dai A, Schrier G, Jones PD, Barichivich J, Briffa KR, Sheffield J (2014) Global warming and changes in drought. Nat Clim Change 4:17-22. doi:10.1038/nclimate2067

Vicente-Serrano SM, Beguería S, López-Moreno JI (2009) A Multiscalar Drought Index sensitive to global warming: the Standardized Precipitation Evapotranspiration Index. J Clim 23:1696-1718. doi:10.1175/ 2009JCLI2909.1

Wang S-Y, Yoon J-H, Gillies RR, Cho C (2013) What caused the winter drought in western Nepal during recent years? J Clim 26:8241-8256. doi:10.1175/JCLI-D-12-00800.1

Wilhite DA (2000) Drought as a natural hazard: concepts and definitions. Routledge, London

Wilhite DA, Svoboda MD, Hayes MJ (2007) Understanding the complex impacts of drought: a key to enhancing drought mitigation and preparedness. Water Resour Manag 21:763-774

Wong G, Lambert M, Leonard M, Metcalfe A (2010) Drought analysis using trivariate copulas conditional on climatic states. J Hydrol Eng 15:129-141. doi:10.1061/(ASCE)HE.1943-5584.0000169

Yatagai A, Kamiguchi K, Arakawa O, Hamada A, Yasutomi N, Kitoh A (2012) APHRODITE: constructing a long-term daily gridded precipitation dataset for Asia based on a dense network of rain gauges. Bull Am Meteorol Soc 93:1401-1415. doi:10.1175/BAMS-D-11-00122.1

Yu X, He X, Zheng H, Guo R, Ren Z, Zhang D, Lin J (2014) Spatial and temporal analysis of drought risk during the crop-growing season over northeast China. Nat Hazards 71:275-289. doi:10.1007/s11069013-0909-2

Yue S, Wang CY (2002) Applicability of prewhitening to eliminate the influence of serial correlation on the MannKendall test. Water Resour Res 38:41-47

Yue S, Pilon P, Cavadias G (2002) Power of the Mann-Kendall and Spearman's rho tests for detecting monotonic trends in hydrological series. J Hydrol 259:254-271. doi:10.1016/S0022-1694(01)00594-7 